\title{
Characterization of urban amine-containing particles in southwestern China: seasonal variation, source, and processing
}

\author{
Yang Chen ${ }^{1,2}$, Mi Tian ${ }^{1}$, Ru-Jin Huang ${ }^{2,3}$, Guangming Shi ${ }^{4}$, Huanbo Wang ${ }^{1}$, Chao Peng ${ }^{1}$, Junji Cao ${ }^{2,3}$, \\ Qiyuan Wang ${ }^{2}$, Shumin Zhang ${ }^{5}$, Dongmei Guo ${ }^{5}$, Leiming Zhang ${ }^{6}$, and Fumo Yang ${ }^{4,1}$ \\ ${ }^{1}$ Research Center for Atmospheric Environment, Chongqing Institute of Green and Intelligent Technology, \\ Chinese Academy of Sciences, Chongqing 400714, China \\ ${ }^{2}$ Key Lab of Aerosol Chemistry \& Physics, State Key Laboratory of Loess and Quaternary Geology, \\ Institute of Earth Environment, Chinese Academy of Sciences, Xi'an 710061, China \\ ${ }^{3}$ Center for Excellence in Quaternary Science and Global Change, Chinese Academy of Sciences, Xi' an 710061, China \\ ${ }^{4}$ National Engineering Research Center for Flue Gas Desulfurization, Department of Environmental Science and Engineering, \\ Sichuan University, Chengdu 610065, China \\ ${ }^{5}$ School of Basic Medical Sciences, North Sichuan Medical College, Nanchong 637000, Sichuan, China \\ ${ }^{6}$ Air Quality Research Division, Science and Technology Branch, Environment and Climate Change Canada, \\ Toronto M3H 5T4, Canada
}

Correspondence: Yang Chen (chenyang@cigit.ac.cn) and Fumo Yang (fmyang@ scu.edu.cn)

Received: 21 October 2018 - Discussion started: 3 December 2018

Revised: 1 March 2019 - Accepted: 4 March 2019 - Published: 13 March 2019

\begin{abstract}
Amine-containing particles were characterized in an urban area of Chongqing during both summer and winter using a single-particle aerosol mass spectrometer (SPAMS). Among the collected particles, $12.7 \%$ were amine-containing in winter and $8.3 \%$ in summer. Amines were internally mixed with elemental carbon (EC), organic carbon (OC), sulfate, and nitrate. Diethylamine (DEA) was the most abundant among amine-containing particles. Wintertime amine-containing particles were mainly from the northwest direction where a forest park was located; in summer, they were from the northwest and southwest (traffic hub) directions. These origins suggest that vegetation and traffic were the primary sources of particulate amines. The average relative peak area of DEA depended strongly on humidity, indicating that the enhancement of DEA was possibly due to increasing aerosol water content and aerosol acidity. Using an adaptive resonance theory neural network (ART-2a) algorithm, four major types of amine-containing particles were clustered: amine-organic carbon (A-OC), AOCEC, DEA-OC, and A-OCEC aged. The identified particle types implied that amines were taken up by particles produced from traffic and biomass burning. The knowledge gained in this study is useful to understand the atmospheric
\end{abstract}

processing, origin, and sources of amine-containing particles in the urban area of Chongqing.

\section{Introduction}

Amines are ubiquitous in the atmosphere and have both natural (ocean, biomass burning, and vegetation) and anthropogenic (animal husbandry, industry, combustion, and traffic) emission sources (Ge et al., 2011a). Trimethylamine (TMA) is one of the most abundant amines with an estimated global emission flux of $170 \mathrm{Gg}_{\text {year }}{ }^{-1}$ (Ge et al., 2011a). Gaseous amines compete with ammonia in acid-base reactions, participate in gas-particle partitioning, and contribute to wet and dry deposition (Angelino et al., 2001; Monks, 2005; Gómez Alvarez et al., 2007; De Haan et al., 2011; Huang et al., 2012; You et al., 2014). Gaseous amines also play an essential role in new particle formation by enhancing the ternary nucleation of $\mathrm{H}_{2} \mathrm{SO}_{4}-\mathrm{H}_{2} \mathrm{O}$ clusters in remote areas (Bzdek et al., 2012; Kirkby et al., 2011). In polluted areas, $\mathrm{H}_{2} \mathrm{SO}_{4}$-diethylamine-water clusters are important during new particle formation events (Yao et al., 2018). Amines are also essential in the growth of ambient parti- 
cles. For example, particulate aminium salts, which are produced via amine-acid neutralization, tend to prevent coagulation between preexisting particles, leading to increased particle number concentrations (Wang et al., 2010; Smith et al., 2010). Moreover, the enrichment of TMA has been observed in cloud and fog processing (Zhang et al., 2012; Rehbein et al., 2011). Characterization of amine-containing particles is important to evaluate their processing and impact.

Single-particle mass spectrometers (SPMSs), such as an aerosol time-of-flight mass spectrometer (ATOFMS) and single-particle aerosol mass spectrometer (SPAMS), have been widely used in real-time measurements of aminecontaining particles for chemical composition and mixing state (Li et al., 2017). SPAMS is different from the Aerodyne soot-particle aerosol mass spectrometer (SP-AMS), which is a type of aerosol mass spectrometer (AMS) for detecting black carbon, sulfate, nitrate, ammonium, chloride, and organics (Onasch et al., 2012; Wang et al., 2016). The chemical composition and mixing state of TMA-containing particles have been reported worldwide, such as in California, USA (Denkenberger et al., 2007; Qin et al., 2012), Ontario, Canada (Tan et al., 2002; Rehbein et al., 2011), Mexico City (Moffet et al., 2008), European cities (Barcelona, Cork, Zurich, Paris, Dunkirk, and Corsica; Healy et al., 2015; Dall'Osto et al., 2016), and Chinese cities such as Guangzhou, Shanghai, and Xi' an (Zhang et al., 2012; Chen et al., 2016; Huang et al., 2012). In the five European cities of Cork, Paris, Dunkirk, Corsica, and Zurich, amines were found internally mixed with sulfate and nitrate; but in Corsica, amines were internally mixed with methanesulfonate (Healy et al., 2015). In Barcelona, five unique types of amine-containing particles were observed: amine-POA58 (composed of amines, sulfate, and nitrate), amine-EST84 (environmental tobacco smoke), amine-SOA59 (composed of TMA and organics), amine-SOA114, and organic nitrogen amines (Dall'Osto et al., 2016, 2013). In a rural area site in the Pearl River Delta (China), the marker ion $\left(\mathrm{C}_{2} \mathrm{H}_{5}\right)_{2} \mathrm{NH}_{2}^{+}$ was the most abundant ( $90 \%$ and $86 \%$ of amine-containing particles in summer and winter) (Cheng et al., 2018). In Guangzhou, TMA-containing particles were important, with up to $7 \%$ in number fraction during clear days and $35 \%$ during fog events (Zhang et al., 2012). In previous studies, reported high RH conditions and fog processing were favorable for the enhancement of trimethylamine in the particle phase. Zhang et al. found that, during fog events, the number fraction of TMA-containing particles was up to $35 \%$; in the size range of $0.5-2.0 \mu \mathrm{m}$, the fraction accounted for up to $60 \%$ (Zhang et al., 2012). Thus, location-specific studies in varied environments are still necessary.

Knowledge of amine-containing particles is limited in southwestern China. In this region, Chongqing is a megacity with a population of 8.23 million. The city is subtropical, industrial, and polluted (Chen et al., 2017; Tao et al., 2017). Fog events frequently occur in this area, and hence it is known as the "fog city" in China. The effect of high rel- ative humidity $(\mathrm{RH})$ on the processing of amine-containing particles needs investigation. This study aims to characterize amine-containing particles, including chemical composition, mixing state, atmospheric processing, and source, in Chongqing during winter and summer.

\section{Methods}

\subsection{Sampling site}

Ambient single particles were collected at an urban air quality supersite from 5 July 2016 to 8 August 2016 (referred to as a summer season) and from 21 January 2016 to 25 February 2016 (referred to as a winter season). The supersite has been described in our previous studies (Chen et al., 2017). Briefly, the supersite is located on the rooftop of a commercial office building $\left(106.51^{\circ} \mathrm{E}, 29.62^{\circ} \mathrm{N}\right)$ at a height of $30 \mathrm{~m}$ above the ground (Fig. S1 in the Supplement). The building is surrounded by business and residential communities and is $15 \mathrm{~km}$ from the city center. A $3 \mathrm{~km}^{2}$ forest park is located northwest of the sampling site and a traffic hub in the southwest.

\subsection{Instrumentation}

A SPAMS (Hexin Inc. Guangzhou, China, model 0515) was deployed for single-particle sampling, and the technical description of SPAMS is available in the literature ( $\mathrm{Li}$ et al., 2011; Chen et al., 2017). Briefly, after passing through a diffusive dryer, particles in a size range of $0.1-2.0 \mu \mathrm{m}$ are sampled via an aerodynamic lens and form a particle beam. Particles in the beam come across two pre-positioned laser beams (Nd:YAG, $532 \mathrm{~nm}$ ) one by one, and the vacuum aerodynamic diameter $\left(D_{\text {va }}\right)$ of each particle is determined via its time of flight. Particles are ionized using an Nd:YAG laser operating at a wavelength of $266 \mathrm{~nm}$. The ions are analyzed using a bipolar time-of-flight mass spectrometer. Due to the limitation of SPAMS, quantification of particulate amines was not attempted.

\subsection{Data analysis}

The SPAMS data were imported into the YAADA toolkit (software toolkit to analyze single-particle mass spectral data, v 2.11) to form a single-particle dataset. A query was conducted using the marker ions of amines: $\mathrm{m} / z 59$ $\left[\left(\mathrm{CH}_{3}\right)_{3} \mathrm{~N}\right]^{+}$(TMA), $74\left[\left(\mathrm{C}_{2} \mathrm{H}_{5}\right)_{2} \mathrm{NH}_{2}\right]^{+}$(diethylamine, DEA), $86\left[\left(\mathrm{C}_{2} \mathrm{H}_{5}\right)_{2} \mathrm{NCH}_{2}\right]^{+}$or $\left[\mathrm{C}_{3} \mathrm{H}_{7} \mathrm{NHC}_{2} \mathrm{H}_{4}\right]^{+}($DEA or DPA), $101\left[\left(\mathrm{C}_{2} \mathrm{H}_{5}\right)_{3} \mathrm{~N}\right]^{+}$(TEA), $102\left[\left(\mathrm{C}_{3} \mathrm{H}_{7}\right)_{2} \mathrm{NH}_{2}\right]^{+}$ (DPA), $114\left[\left(\mathrm{C}_{3} \mathrm{H}_{7}\right)_{2} \mathrm{NCH}_{2}\right]^{+}$(DPA), and $143\left[\left(\mathrm{C}_{3} \mathrm{H}_{7}\right)_{3} \mathrm{~N}\right]^{+}$ (TPA) (Healy et al., 2015). Firstly, $m / z 59$ was used for querying the TMA-containing particles, followed by $m / z 74$ for DEA-containing particles, $m / z 86$ for TEA-containing particles, and so on. The query strategy resulted in duplicate particles in the results when various amines coexisted in one 
single amine-containing particle. After the duplicate particles were removed from the multiple query results described above, all amine-containing particles were combined into an amine-containing particle cluster. Various amines could be both internally and externally mixed in these particle clusters.

An neural network algorithm based on adaptive resonance theory (ART-2a) was applied to cluster the amine-containing particle types using a vigilance factor of 0.70 , a learning rate of 0.05 , and 20 iterations (Song et al., 1999). This procedure produced 67 clusters in summer and 75 clusters in winter; many of these clusters exhibited identical mass spectra with slight differences in specific ion intensities. A wellestablished combining strategy, on the basis of similar mass spectra, temporal trends, and size distribution, was adopted to merge these particle clusters into the finalized particle types (Dallosto and Harrison, 2006). In addition, the relative peak area (RPA) is defined as the peak area of each $m / z$ divided by the total dual-ion mass spectral peak areas of each particle (Healy et al., 2013). To calculate the overall RPA of amines, the relative peak areas of amines in each particle were extracted and summed up.

\section{Results and discussion}

\subsection{Single-particle chemical composition and seasonal variation}

The percentage of amine-containing particles was $12.7 \%$ in the winter SPAMS dataset and $8.3 \%$ in the summer dataset. DEA-containing particles were dominant, accounting for $70 \%$ and $78 \%$ of all amine-containing particles in winter and summer, respectively; while TMA-containing particles were minor, accounting for up to $7 \%$ in winter and $3 \%$ in summer among all the amine-containing particles. The average mass spectra of DEA-, DPA-, and TMA-containing particles are provided in Fig. S2, and these spectra showed strong homogeneity. The determination coefficient $\left(R^{2}\right)$ between DEA- and DPA-containing particles was 0.98 , and $R^{2}$ between DEA- and TMA-containing particles was 0.83 .

Figure 1 shows the digital mass spectra of aminecontaining particles in two seasons. In each spectrum, the ion height indicates its fraction in the amine-containing particle dataset, and the stacked color map shows the corresponding ion intensity ranges. The assignment of ions is shown in Table S1. In both seasons, the dominant ions were $\mathrm{K}^{+}$ $(\mathrm{m} / z 39$ and 41$)$, amines $(\mathrm{m} / z$ 59, 74, and 86), and organics $(\mathrm{m} / z$ 43, 51, 63, and 77). The mixing ratios of ammonium $\left(\mathrm{NH}_{4}^{+}, m / z, 18\right)$ and polycyclic aromatic hydrocarbons (e.g., $m / z 116\left(\left[\mathrm{C}_{9} \mathrm{H}_{8}\right]^{+}\right), 129\left(\left[\mathrm{C}_{10} \mathrm{H}_{9}\right]^{+}\right), 140\left(\left[\mathrm{C}_{11} \mathrm{H}_{8}\right]^{+}\right)$, and $\left.153\left(\left[\mathrm{C}_{12} \mathrm{H}_{9}\right]^{+}\right)\right)$were higher in winter than in summer. The strong signal of $\mathrm{NH}_{4}^{+}$was possibly due to the lower temperature $\left(8^{\circ} \mathrm{C}\right)$ in winter than in summer $\left(31^{\circ} \mathrm{C}\right)$. The mixing ratios of $m / z 59$ were $45 \%$ and $44 \%$ during summer and winter, respectively.

In the negative mass spectra of two seasons (Fig. $1 \mathrm{~b}$ and d), the dominant ions were $\mathrm{CN}^{-}(m / z-26), \mathrm{CNO}^{-}(\mathrm{m} / z-42)$, nitrate $(m / z-46$ and -62$)$, phosphate $(-79)$, and sulfate $(m / z-80$ and -97$)$. Primary species, such as $\mathrm{CN}^{-}$and $\mathrm{CNO}^{-}$, were commonly from biomass burning (BB) and organo-nitrogen (Pratt et al., 2011). Levoglucosan markers from $\mathrm{BB}$, such as $-45,-59$, and -71 , were also detected. Dust markers, such as $\left[\mathrm{SiO}_{2}\right]^{-}(m / z-60),\left[{ }^{28} \mathrm{SiO}_{3}\right]^{-}$or $\left[\mathrm{AlO}_{2}(\mathrm{OH})\right]^{-}(-76)$, and $\left[\mathrm{PO}_{3}\right]^{-}$, were also detected during summertime, suggesting the influence of dust particles.

Prior to comparison, the ion peak was normalized using the method developed by Qin et al. (2012). Briefly, the peak area of each $m / z$ was divided by the total mass spectral peak area matrix. The normalized ion intensity of the wintertime particles was subtracted from that of the summertime particles. A positive value indicates that the normalized ion intensity was greater in the summer, whereas a negative value indicates that the normalized ion intensity was greater in the winter. As shown in Fig. S3, $\mathrm{Ca}^{+}(m / z 40)$ and $\mathrm{Fe}^{+}(m / z$ 56) were more prevalent during summer. Organic species, such as $\mathrm{C}_{2} \mathrm{H}_{3}^{+}(m / z 27), \mathrm{C}_{4} \mathrm{H}_{3}^{+}(m / z 51), \mathrm{C}_{5} \mathrm{H}_{3}^{+}(m / z 63)$, and $\mathrm{C}_{6} \mathrm{H}_{5}^{+}(m / z, 77)$ typically from aromatic hydrocarbons, were also more abundant in summer. During wintertime, signals of sulfate $(m / z-97), \mathrm{NO}_{3}^{-}(m / z-62), \mathrm{NH}_{4}^{+}(m / z$ 18), and $\mathrm{K}^{+}(m / z 39)$ were more prominent than in summer, suggesting that the wintertime particles contained more secondary species than those in summer.

The unscaled size distribution of amine-containing particles also showed strong seasonal variations (Fig. S4). Generally, amine-containing particles had monomodal size distributions in the droplet mode, and the distributions peaked at a larger $D_{\text {va }}$ in summer than winter. For example, DEAcontaining particles peaked at $0.6 \mu \mathrm{m}$ in winter and $0.8 \mu \mathrm{m}$ in summer, and DPA-containing particles at $0.7 \mu \mathrm{m}$ in winter and $0.9 \mu \mathrm{m}$ in summer. The size distributions of the major amine-containing particles suggested that these particles had undergone substantial aging processes.

\subsection{Temporal trend, diurnal pattern, and origin of amine-containing particles}

Figure 2 shows the temporal tends of RH, temperature, number count, and the peak area of amine-containing particles. The winter temperature was lower $\left(8.0 \pm 4.0^{\circ} \mathrm{C}\right)$ than summer $\left(31 \pm 4^{\circ} \mathrm{C}\right)$, and $\mathrm{RH}$ in the winter was slightly higher $(70 \pm 14 \%$ versus $64 \pm 16 \%)$ (Table 1). Stagnant air conditions occurred in both seasons due to low wind speeds (Huang et al., 2017), and the winter wind speed was lower than in summer. The hourly count of amine-containing particles was typically 10 times higher in winter than summer.

In winter, a good correlation existed between the temporal trends of hourly number count and peak area of DEAcontaining particles $\left(R^{2}=0.86\right)$. The corresponding $R^{2}$ in 
(a)

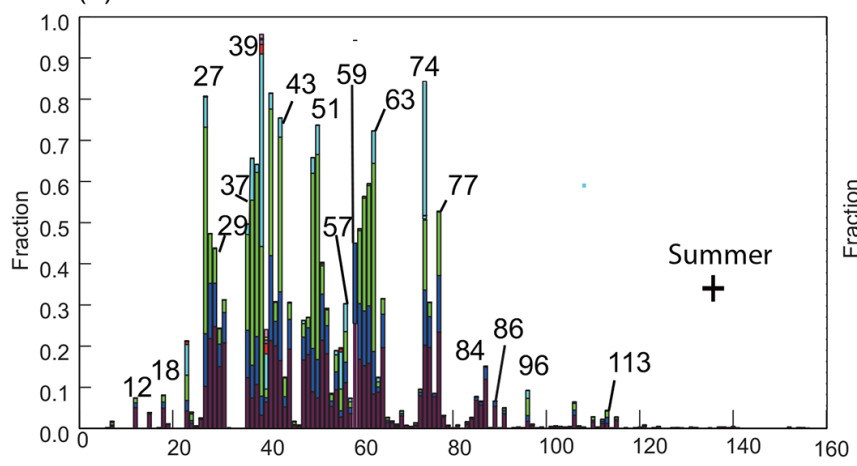

(c)

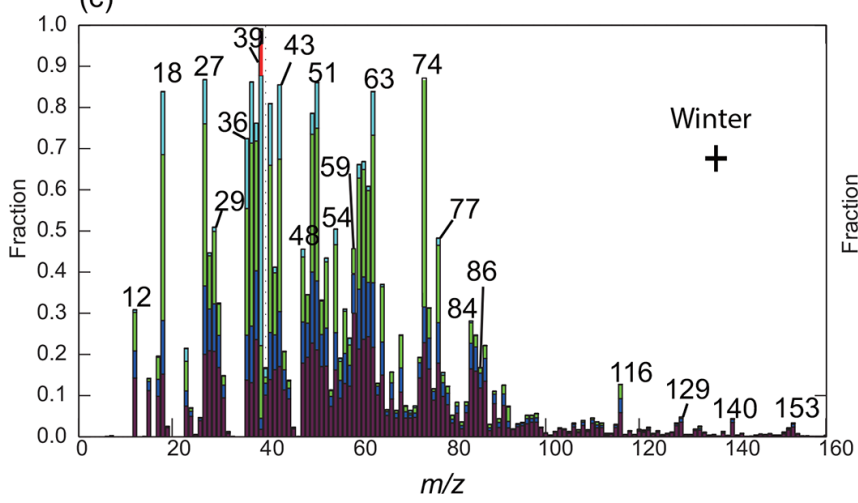

(b)

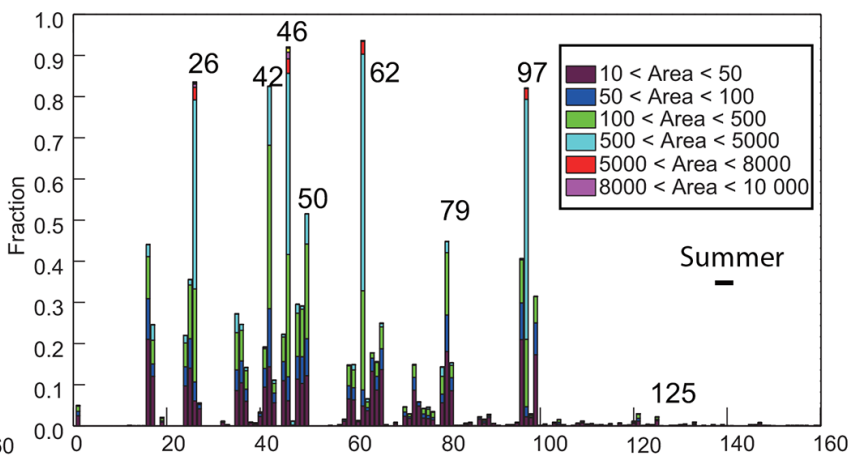

(d)

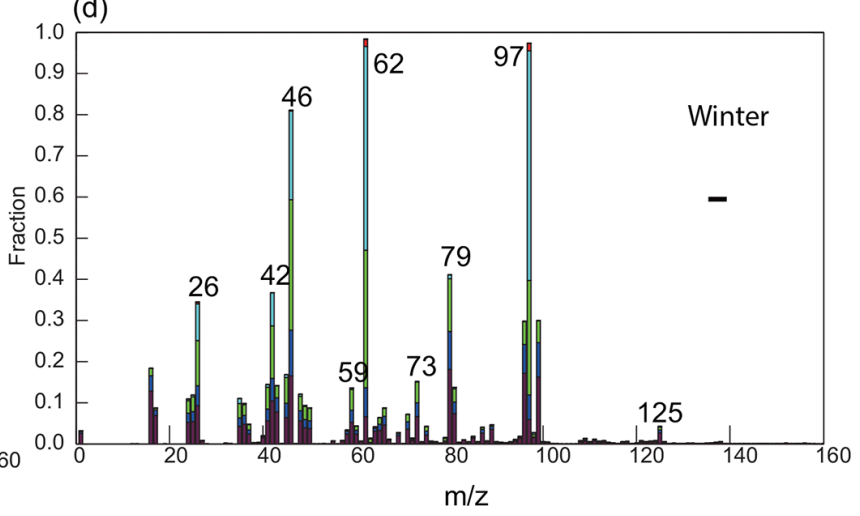

Figure 1. (a, c) The positive digital mass spectrum of amine-containing particles during summer and wintertime, respectively; (b, d) the negative digital mass spectrum during summer and wintertime, respectively. The ion height indicates its fraction in the amine-containing particle dataset, and the stacked color map indicates the ion peak area range.

Table 1. Meteorological factors and particle counts in summer and winter.

\begin{tabular}{lrr}
\hline & Winter & Summer \\
\hline Temperature $\left({ }^{\circ} \mathrm{C}\right)$ & $8 \pm 4$ & $31 \pm 4$ \\
Relative humidity $(\%)$ & $70 \pm 14$ & $64 \pm 16$ \\
Wind speed & $1.2 \pm 0.7$ & $1.5 \pm 1.0$ \\
Amine particle count $\left(\right.$ no. $\left.^{-1}\right)$ & $587 \pm 384$ & $47 \pm 26$ \\
\hline
\end{tabular}

wintertime DPA-containing particles was 0.88 . No such correlation for TMA-containing particles was observed in winter $\left(R^{2}=0.22\right)$ or summer (Fig. 2). The hourly counts of DEA- and DPA-containing particles were well correlated in both summer $\left(R^{2}=0.63\right)$ and winter $\left(R^{2}=0.87\right)$, but a weak correlation $\left(R^{2}=0.25\right)$ existed between DEA- and TMA-containing particles. These results suggest that DEAand DPA-containing particles were possibly from the same sources.

DEA- and DPA-containing particles remained at low levels from 20 to 26 January 2016 and averaged at 109 and 26 count $^{-1}$, respectively. During this period, wind speed was relatively high, commonly above $1.5 \mathrm{~m} \mathrm{~s}^{-1}$. TMA-, DEA-, and DPA-containing particles started accumulating after 26 January 2016 when wind speed was low $\left(0.8 \mathrm{~m} \mathrm{~s}^{-1}\right)$ and wind direction was from the northwest. After 3 February 2016, DEA- and DPA-containing particles showed regular diurnal patterns with high levels of hourly count during daytime on most days and minimum levels at 15:00 local time (UTC+8). A similar diurnal pattern was also observed for DPA-containing particles during wintertime (Fig. 3). TMAcontaining particles presented a complex diurnal profile with peaks in the early morning (04:00), at noon (12:00), and in the afternoon (18:00). The chemical composition and diurnal pattern of TMA-containing particles were strongly connected to traffic emissions.

Wind direction and the number count of amine-containing particles were analyzed together using bivariate polar plots (Fig. 4). During wintertime, the dominant direction for amine-containing particles was from the northwest where a forest park was located. After being emitted from vegetation (plants, grass, and trees) (Ge et al., 2011a), DEA could partition to preexisting particles before arriving at the sampling site. The transport of these particles to the sampling site caused the elevation in the morning. Based on the excellent correlation between DEA- and DPA-containing particles, DPA-containing particles could also be from vegetation. It can be concluded that the major source of amines in DEA- 

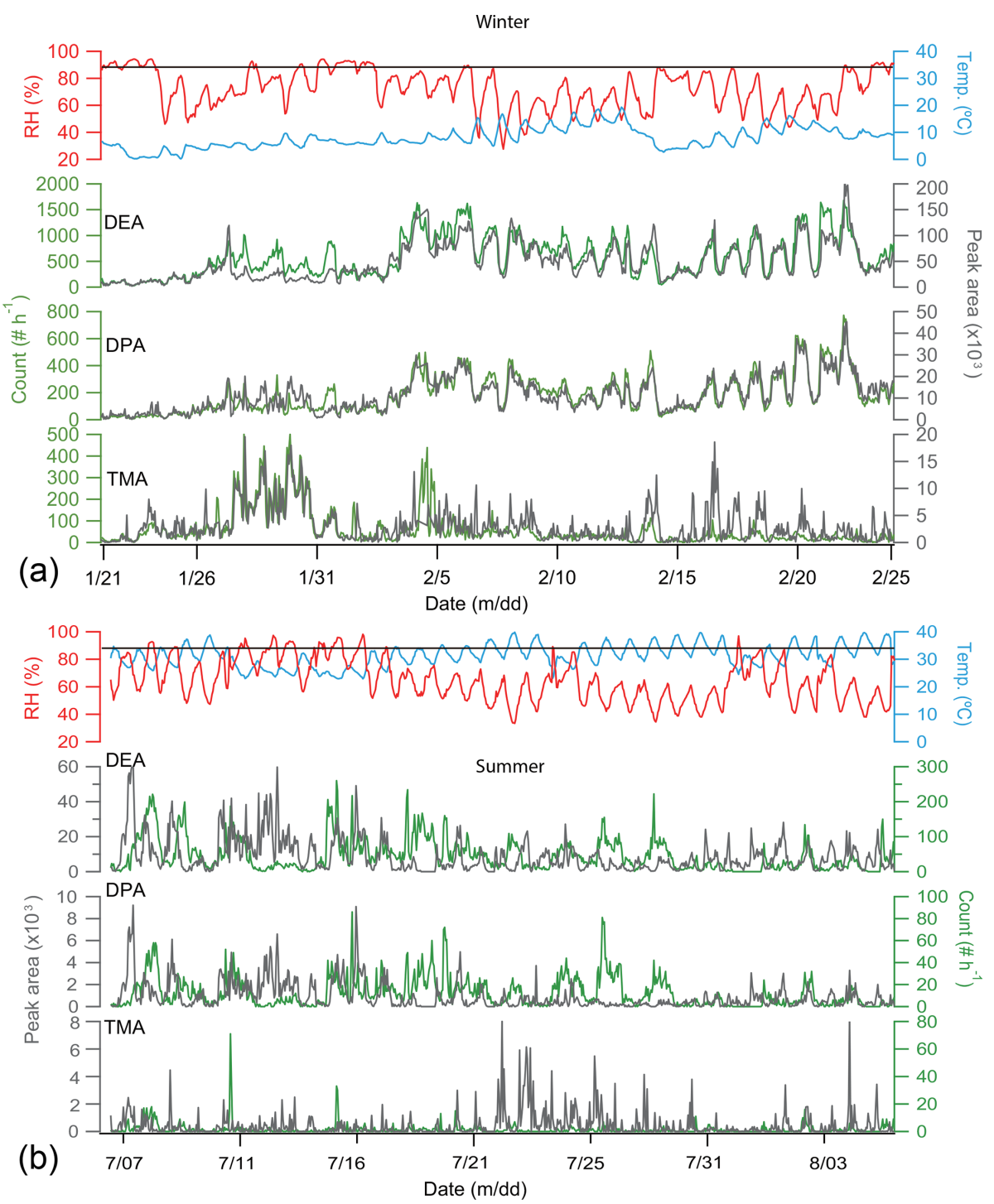

Figure 2. Temporal trends of relative humidity (RH), temperature (Temp.), hourly peak area (dark gray), and particle count (green) of particles containing DEA $(m / z 74)$, DPA $(m / z$ 86), and TMA $(m / z 59)$ in winter (a) and summer (b). The black lines in the two panels indicate $\mathrm{RH}$ of $90 \%$.

and DPA-containing particles was vegetation from the northwest.

During summer, amine particles appeared in several episodes; each episode lasted for 1-3 days. In these episodes, DPA-containing particles had two rush-hour peaks (07:00 and 17:00), likely from traffic (Dall'Osto et al., 2016). Besides traffic, vegetation is also a source of DPA-containing particles (from the southwest; Fig. 4e). The DPA-containing particles peaked $0.84 \mu \mathrm{m}$, suggesting that they were not freshly emitted and had undergone substantial aging processes. Moreover, as shown in Fig. S2, the mass spectra of the amines were present with aromatic hydrocarbon fragments, such as $\mathrm{C}_{4} \mathrm{H}_{3}^{+}(m / z 51), \mathrm{C}_{5} \mathrm{H}_{3}^{+}(m / z 63), \mathrm{C}_{6} \mathrm{H}_{5}^{+}(m / z$ 77), and $\mathrm{C}_{9} \mathrm{H}_{8}^{+}(m / z 116)$, as well as with alkane fragments such as $\mathrm{C}_{4} \mathrm{H}_{7}^{+}(m / z 55), \mathrm{C}_{4} \mathrm{H}_{9}^{+}(m / z 57)$, and $\mathrm{C}_{5} \mathrm{H}_{9}^{+}(m / z$ 69).
The chemical composition of DPA-containing particles contained markers associated with traffic emissions. A similar amine-containing particle type has been reported in the literature (Dall'Osto et al., 2016).

In summer, DEA-containing particles had a diurnal pattern of three peaks appearing at 03:00, 09:00, and 17:00. TMA-containing particles had an early morning (04:00) and a noon peak (12:00). The morning peaks of DEA- and TMAcontaining particles could be due to local traffic emissions; specifically, heavy-duty vehicles were only allowed to enter the urban area between 00:00 and 06:00 (Chen et al., 2017). The polar plots showed that DEA-containing particles were from the northwest and southwest, passing through the forest park and traffic hub, respectively. This scenario seemed to be inconsistent with the wintertime results because of the 

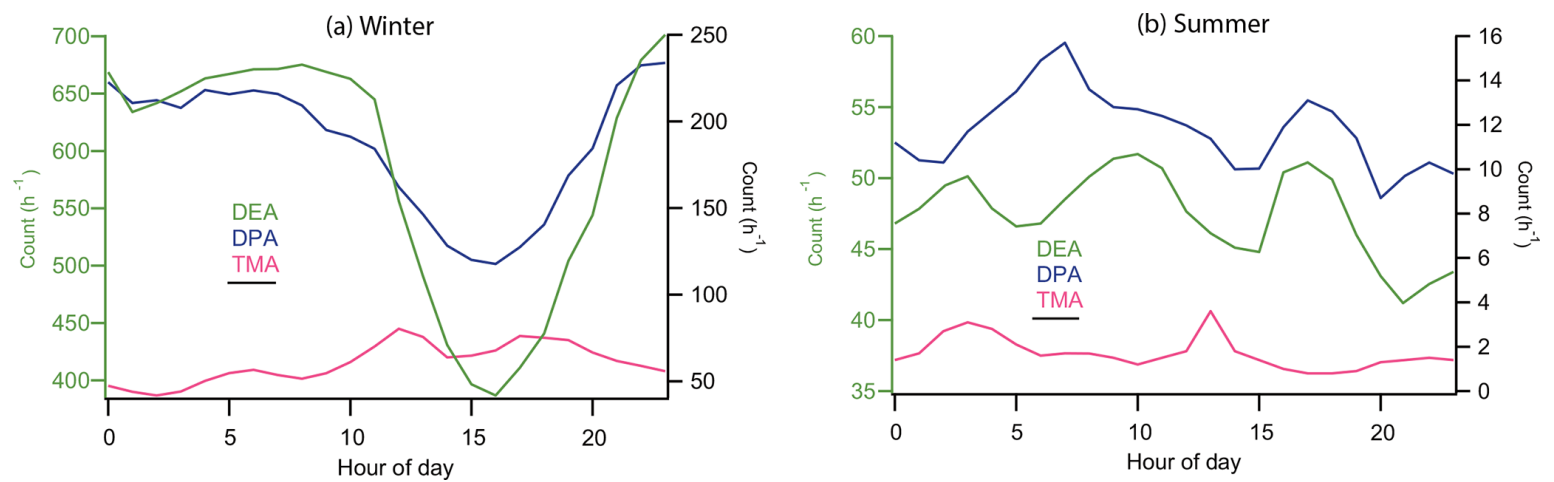

Figure 3. Diurnal profiles of amine-containing particles during both winter (a) and summer (b). The green left axis in each panel indicates the average number count of DEA-containing particles, while the right axis represents the number count of both DPA- and TMA-containing particles.

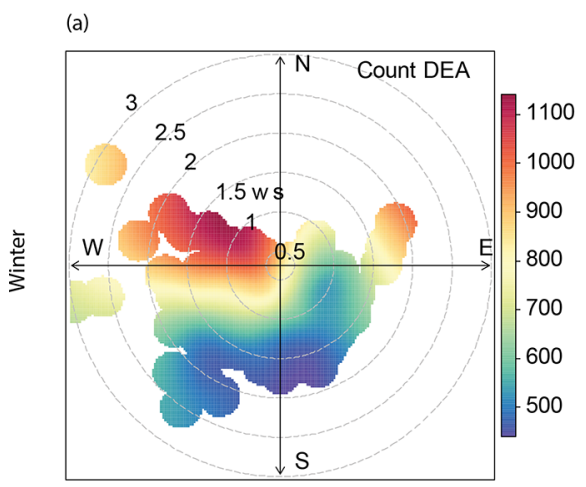

(b)

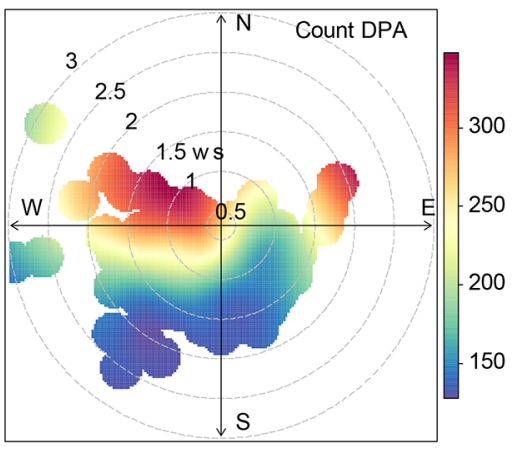

(e)

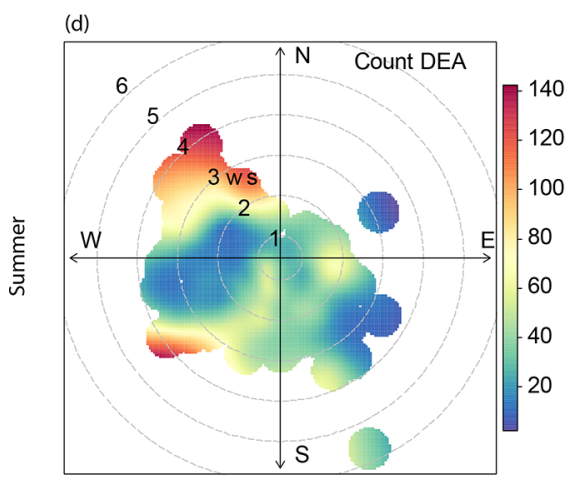

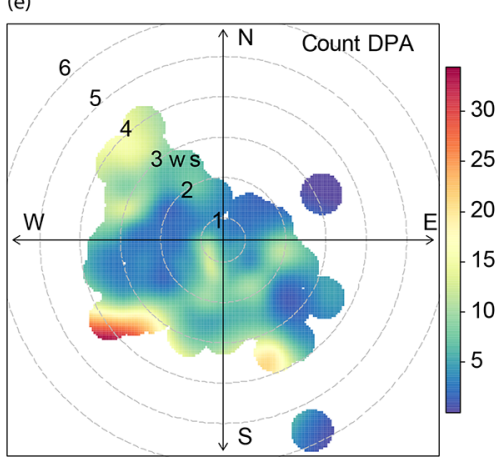

(c)

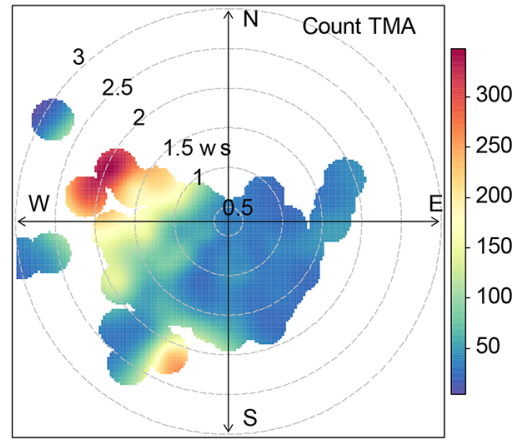

(f)

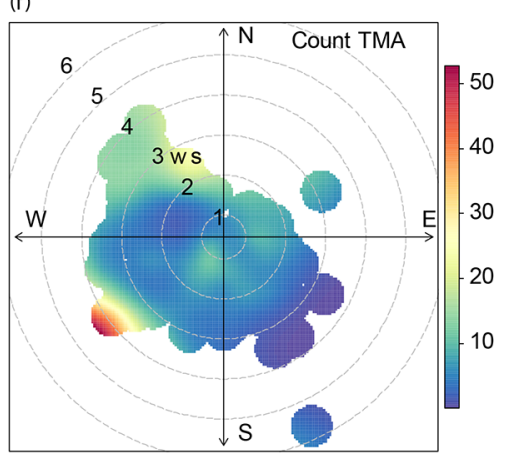

Figure 4. Polar plots of amine-containing particles during winter and summertime. The axes in each figure indicate hourly count of each particle type, and the colors within the circles represent wind speed (ws).

limited traffic contributions to particle levels in winter. In addition, due to the competition between vegetation and traffic in summer, the number count and peak area of all three amine-containing particles were poorly correlated with each other.

\subsection{Effect of RH on the enrichment of DEA-containing particles}

DEA-containing particles were predominant in both winter and summer, providing a unique opportunity for investigat- ing DEA processing. Indeed, the effect of $\mathrm{RH}$ on aerosol chemical processing should be treated cautiously and the influences of wind speed, wind direction, temperature, and planetary boundary layer reduction should be removed. As described above, the average wind speed in winter and summer was 1.2 and $1.5 \mathrm{~m} \mathrm{~s}^{-1}$, respectively. In these stagnant air conditions, the sampled particles were generally local. Temperature could influence gas-particle phase partitioning. Assuming that the Henry's law constants $\left(K_{\mathrm{H}}\right)$ and the enthalpy change $\Delta_{r} H_{o}\left(K_{\mathrm{H}}\right)$ of DEA are constant, a variation 
of $10^{\circ} \mathrm{C}$ in both summer and winter has a negligible influence on the partitioning of amines from the gas phase to the particle phase, according to the Clapeyron equation ( $\mathrm{Ge}$ et al., 2011b). In addition, the shift in planetary boundary layer (PBL) height could affect the number count and concentration of PM. Using the temporal trends of RPA, the influence of PBL height can be removed because it only shows the relative changes between different species, which are all simultaneously influenced by the shift in the PBL height.

Box plots of DEA relative peak area under different RH are shown in Fig. 5. In winter, the median RPA of aminecontaining particles increased by 2 times when $\mathrm{RH}$ increased from $35 \%$ to $95 \%$. Meanwhile, the fraction of DEAcontaining particles increased from $4.0 \%$ to $16.6 \%$. In summer, the average RPA of DEA increased by 3 times (from 0.25 to 0.75 ), and the fraction of DEA-containing particles increased from $3.8 \%$ to $12.1 \%$ when $\mathrm{RH}$ increased from $60 \%$ to $90 \%$. These results suggest that RH is important to the enrichment of DEA in the particle phase. When DEA reacts with $\mathrm{HCl}, \mathrm{H}_{2} \mathrm{SO}_{4}$, and $\mathrm{HNO}_{3}$, it tends to form aminium salts, which are soluble in aerosol water. Along with the influence of aerosol water content, Ge et al. (2011a) also proposed that strong aerosol acidity could enhance the partitioning of DEA in the aqueous phase. As particles are dried in the SPAMS, the amounts of aerosol water content and $\mathrm{pH}$ were unavailable. Values of the anion-to-cation ratio ((sulfate + nitrate) / ammonium; Yao et al., 2011) were in a range of 20-150, suggesting that the particles might have been acidic, which favors the dissolution of DEA. Overall, these results implied that high $\mathrm{RH}$ conditions in Chongqing were favorable for particle uptake of DEA, and the resulting formation of aminium salts stabilized preexisting particles, thus increasing their number concentrations.

Rehbein et al. (2011) and Zhang et al. (2012) observed direct links between fog processing and enhancement of TMAcontaining particles. High RH conditions were favorable for TMA entering the particle phase via gas-particle partitioning (Rehbein et al., 2011; Zhang et al., 2012). Ge et al. (2011b) argued that TMA in the aerosol phase was in the form of free base, e.g., amine, not aminium salt; TMA could be dissolved in aerosol water and the formation of TMA- $-\mathrm{HSO}_{4}$ salt was possible, but the formation of TMA- $\mathrm{NO}_{3}$ and TMA-Cl was impossible due to competition with ammonia. Thus, TMA could enter the aerosol phase by gas-aqueous partitioning or in the form of TMA-HSO 4 salt. The mechanism of DEA entering the aerosol phase might be different from TMA. DEA salts were favorable for forming in the aerosol phase (Ge et al., 2011b). Pankow (2015) proposed that the absorptive uptake of atmospheric amines could also be possible on organic aerosols. In the context of single-particle mixing state, the amine-containing particles were internally mixed with hygroscopic species, e.g., sulfate, nitrate, $\mathrm{POA}$ species $\left(\mathrm{C}_{x} \mathrm{H}_{y}^{+}\right.$; see Sect. 3.4), and SOA species (oxalate, $\mathrm{C}_{2} \mathrm{H}_{3} \mathrm{O}^{+}$). Therefore, the mixing state of amine-containing particles was also favorable for the uptake of amines via different pathways: the
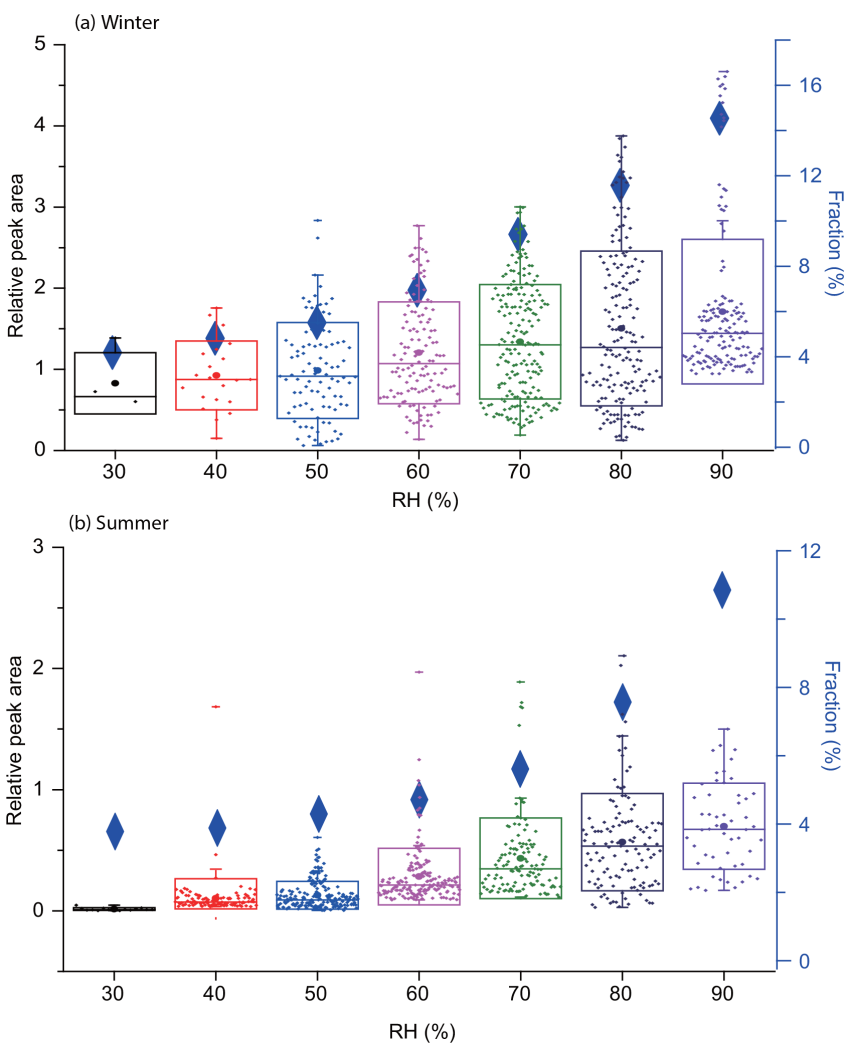

Figure 5. Box plots of the hourly relative peak area of DEA under different RH conditions in winter (a) and summer (b). The boxes indicate the 25th and 75th percentiles; the dots indicate mean value with each data point representing a datum of RPA in an hour size bin. Right axis in each panel and the blue diamonds show the average number fraction of amine-containing particles among the whole SPAMS dataset.

aqueous dissolution of aminium salts and absorptive uptake on OA.

\subsection{Particle types of amine-containing particles}

As shown in Fig. 6, four amine-containing particle types were resolved, including amine-OC (A-OC, $41 \%)$, A-ECOC $(39 \%)$, DEA-OC $(11 \%)$, and A-ECOC aged $(9 \%)$. All of these particle types had strong signals of amines, and the amines were internally mixed with sulfate, nitrate, elemental carbon, and organics.

In the A-OC particles, amines were mixed with aromatic hydrocarbon fragments, such as $\mathrm{C}_{4} \mathrm{H}_{3}^{+}(m / z 51), \mathrm{C}_{5} \mathrm{H}_{3}^{+}$ $(m / z 63), \mathrm{C}_{6} \mathrm{H}_{5}^{+}(m / z 77)$, and $\mathrm{C}_{9} \mathrm{H}_{8}^{+}(m / z 116)$, as well as with alkanes fragments such as $\mathrm{C}_{4} \mathrm{H}_{7}^{+}(m / z 55), \mathrm{C}_{4} \mathrm{H}_{9}^{+}$ $(m / z 57)$, and $\mathrm{C}_{5} \mathrm{H}_{9}^{+}(m / z 69)$. In the negative mass spectrum of A-OC, strong signals from $\mathrm{CN}^{-}(m / z-26)$ and $\mathrm{CNO}^{-}$ $(m / z-42)$ were typically primary species, along with levoglucosan (Silva et al., 1999). The amine fragments, such as TMA $(m / z 59)$, DEA $(m / z 74)$, and DPA $(m / z 86)$, were very abundant in this particle type $(76 \%, 95 \%$, and $88 \%$, re- 
(a)
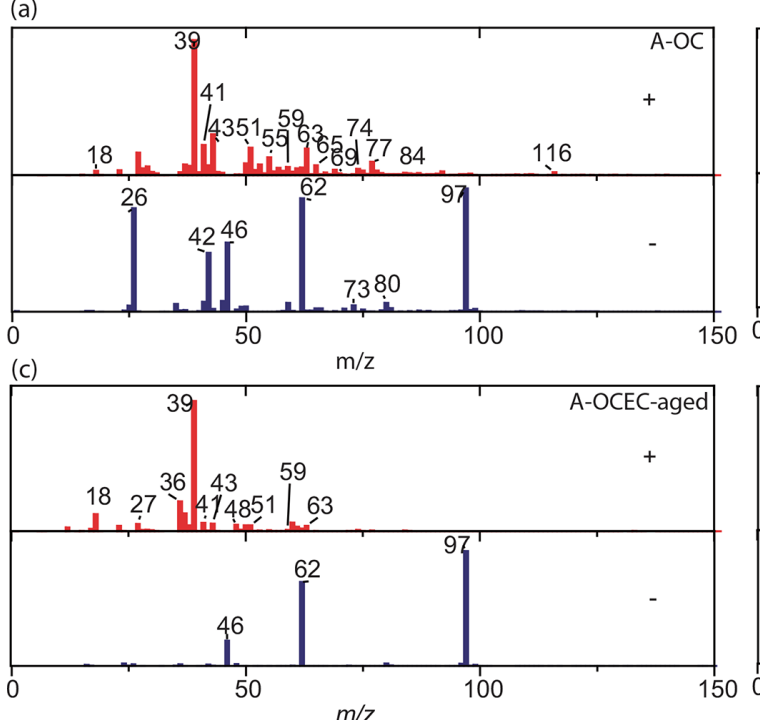

(b)
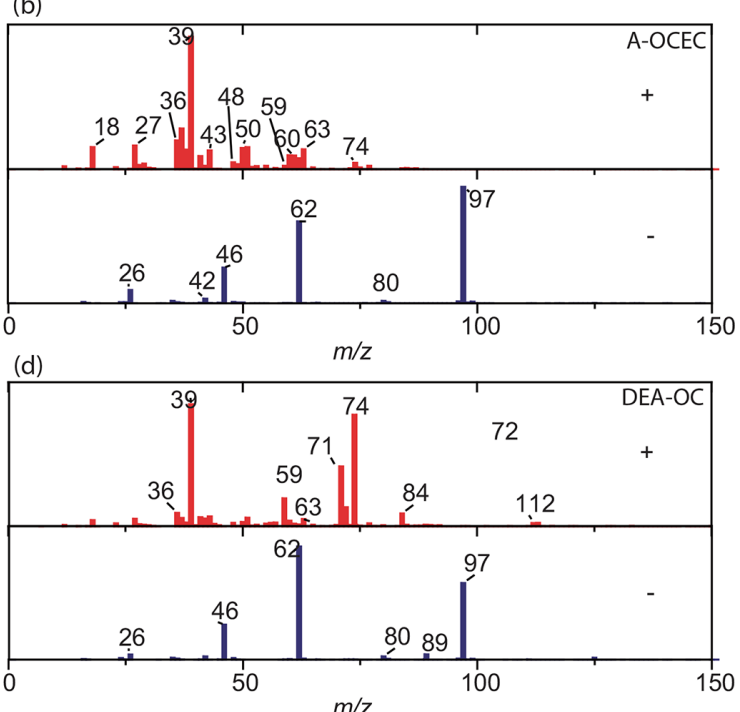

Figure 6. Average mass spectra of major particle types clustered from amine-containing particles.

spectively). The parent particles of A-OC were a kind of OC particle from biomass burning; then they mixed with amines via uptake. Amines could enter the A-OC particle type via dissolution in the aerosol water content or uptake due to absorptive uptake on the organic aerosol (Pankow, 2015).

In A-ECOC mass spectra, strong signals of amines $(\mathrm{m} / \mathrm{z} 59$ and 74$)$, along with the major aromatic hydrocarbon fragments and EC components (i.e., $m / z$ 36, 48, 60), were detected. In the negative mass spectra, nitrate and sulfate were also dominant. The A-ECOC aged particle type had a similar chemical composition to A-ECOC $\left(R^{2}=0.53\right)$ but with weaker relative intensities of $\mathrm{C}_{\mathrm{x}} \mathrm{H}_{\mathrm{y}}^{+}$and amine ions, suggesting it could be more secondary.

In the positive mass spectra of DEA-OC, the DEA fragment $(m / z$ 74) was dominant and present with the organic fragments described above. Secondary organic marker ions, such as $m / z 43\left(\left[\mathrm{C}_{2} \mathrm{H}_{3} \mathrm{O}\right]^{+}\right)$and -89 (oxalic acid), were found in the mass spectra. DEA-OC was not sensitive to wind speed $\left(R^{2}=0.18\right)$, implying they were local.

The summertime amine-containing particles were similar to the particle types during winter (all $R^{2}>0.7$ ), except that a Ca-rich particle type was also resolved (Fig. S5). The ACa-OC particle type was mainly composed of calcium $\left(\mathrm{Ca}^{+}\right.$ and $\left.\mathrm{CaO}^{+}\right)$, sodium $(m / z 23)$, potassium $(m / z$ 39), TMA $(m / z 59)$, sulfate, nitrate, and phosphate. An ion signal of zinc $(m / z 64)$ was observed in the positive mass spectrum. $\mathrm{Zn}$ is a marker for tire wear on roads (Grigoratos and Martini, 2015; Thorpe and Harrison, 2008). The A-Ca-OC particle type was possibly from traffic activities (Chen et al., 2017).

The amine-containing particle types reported in this study are different from those in the literature. Cheng et al. (2018) reported that $m / z 74$ amine-containing particles were most abundant in the Pearl River Delta, China, but the chemical composition and mixing state of amine particles were different from this study. For example, the mixing ratio of DPA was much stronger $(\sim 0.2)$ in Guangdong than in Chongqing $(<0.1)$. In most related studies, TMA-containing particles were dominant, while the present study shows that DEAcontaining particles were dominant (Rehbein et al., 2011; Zhang et al., 2012; Healy et al., 2015; Dall'Osto et al., 2016).

\section{Conclusions}

Amine-containing particles were collected and analyzed during winter and summer in the urban area of Chongqing. Generally, amine-containing particles were more abundant in winter than in summer. DEA-containing particles $(m / z 74)$ were the most important particle type during both summer and winter. Amines were internally mixed with EC components, organics, sulfate, and nitrate, suggesting that particle aging was significant in both seasons. Amine-containing particles had monomodal size distributions in the droplet mode, and the distributions peaked at a larger $D_{\mathrm{va}}$ in summer than winter. DEA- and DPA-containing particles showed strong homogeneity, and good correlations between the hourly number count and peak area were observed during winter. The amine-containing particles were mostly from vegetation located southwest of the sampling area and traffic sources in the northwest. An enrichment of DEA-containing particles under high RH conditions was revealed. Reduction of anthropogenic amines, such as DEA and TMA, would improve the air quality in this region, which can be achieved by decreasing the emissions of on-road fuel-powered automobiles. 
Data availability. All data described in this study are available upon request from the corresponding authors.

Supplement. The supplement related to this article is available online at: https://doi.org/10.5194/acp-19-3245-2019-supplement.

Author contributions. YC and FY designed the experiments; MT, GS, CP, HW, and QW carried them out; RH, YC, LZ, JC, SZ, and DG analyzed the experimental data; YC prepared the paper with contributions from all coauthors.

Competing interests. The authors declare that they have no conflict of interest.

Acknowledgements. Financial support from the National Key Research and Development Program of China (2018YFC0200403 and 2016YFC0200405), the Nature Science Foundation of China (grant no. 41375123), and the Educational Commission of Sichuan Province of China (no. 15ZA0213) is acknowledged.

Review statement. This paper was edited by Barbara Ervens and reviewed by two anonymous referees.

\section{References}

Angelino, S., Suess, D. T., and Prather, K. A.: Formation of aerosol particles from reactions of secondary and tertiary alkylamines: characterization by aerosol time-of-flight mass spectrometry, Environ. Sci. Technol., 35, 3130-3138, https://doi.org/10.1021/es0015444, 2001.

Bzdek, B. R., Zordan, C. A., Pennington, M. R., Luther III, G. W., and Johnston, M. V.: Quantitative assessment of the sulfuric acid contribution to new particle growth, Environ. Sci. Technol., 46, 4365-4373, https://doi.org/10.1021/es204556c, 2012.

Chen, Y., Cao, J., Huang, R., Yang, F., Wang, Q., and Wang, Y.: Characterization, mixing state, and evolution of urban single particles in Xi'an (China) during wintertime haze days, Sci. Total Environ., 573, 937-945, https://doi.org/10.1016/j.scitotenv.2016.08.151, 2016.

Chen, Y., Yang, F., Mi, T., Cao, J., Shi, G., Huang, R., Wang, H., Chen, J., Lou, S., and Wang, Q.: Characterizing the composition and evolution of and urban particles in Chongqing (China) during summertime, Atmos. Res., 187, 8494, https://doi.org/10.1016/j.atmosres.2016.12.005, 2017.

Cheng, C., Huang, Z., Chan, C. K., Chu, Y., Li, M., Zhang, T., Ou, Y., Chen, D., Cheng, P., Li, L., Gao, W., Huang, Z., Huang, B., Fu, Z., and Zhou, Z.: Characteristics and mixing state of amine-containing particles at a rural site in the Pearl River Delta, China, Atmos. Chem. Phys., 18, 9147-9159, https://doi.org/10.5194/acp-18-9147-2018, 2018.

Dallosto, M. and Harrison, R.: Chemical characterisation of single airborne particles in Athens (Greece) by ATOFMS, Atmos. Environ., 40, 7614-7631, https://doi.org/10.1016/j.atmosenv.2006.06.053, 2006.

Dall'Osto, M., Querol, X., Alastuey, A., Minguillon, M. C., Alier, M., Amato, F., Brines, M., Cusack, M., Grimalt, J. O., Karanasiou, A., Moreno, T., Pandolfi, M., Pey, J., Reche, C., Ripoll, A., Tauler, R., Van Drooge, B. L., Viana, M., Harrison, R. M., Gietl, J., Beddows, D., Bloss, W., O'Dowd, C., Ceburnis, D., Martucci, G., Ng, N. L., Worsnop, D., Wenger, J., Mc Gillicuddy, E., Sodeau, J., Healy, R., Lucarelli, F., Nava, S., Jimenez, J. L., Gomez Moreno, F., Artinano, B., Prévôt, A. S. H., Pfaffenberger, L., Frey, S., Wilsenack, F., Casabona, D., Jiménez-Guerrero, P., Gross, D., and Cots, N.: Presenting SAPUSS: Solving Aerosol Problem by Using Synergistic Strategies in Barcelona, Spain, Atmos. Chem. Phys., 13, 8991-9019, https://doi.org/10.5194/acp13-8991-2013, 2013.

Dall'Osto, M., Beddows, D. C. S., McGillicuddy, E. J., Esser-Gietl, J. K., Harrison, R. M., and Wenger, J. C.: On the simultaneous deployment of two single-particle mass spectrometers at an urban background and a roadside site during SAPUSS, Atmos. Chem. Phys., 16, 9693-9710, https://doi.org/10.5194/acp16-9693-2016, 2016.

De Haan, D. O., Hawkins, L. N., Kononenko, J. A., Turley, J. J., Corrigan, A. L., Tolbert, M. A., and Jimenez, J. L.: Formation of nitrogen-containing oligomers by methylglyoxal and amines in simulated evaporating cloud droplets, Environ. Sci. Technol., 45, 984-991, https://doi.org/10.1021/es102933x, 2011.

Denkenberger, K. A., Moffet, R. C., Holecek, J. C., Rebotier, T. P., and Prather, K. A.: Real-time, single-particle measurements of oligomers in aged ambient aerosol particles, Environ. Sci. Technol., 41, 5439-5446, https://doi.org/10.1021/es0703291, 2007.

Ge, X., Wexler, A. S., and Clegg, S. L.: Atmospheric amines - Part I. A review, Atmos. Environ., 45, 524-546, https://doi.org/10.1016/j.atmosenv.2010.10.012, $2011 \mathrm{a}$.

Ge, X., Wexler, A. S., and Clegg, S. L.: Atmospheric amines - Part II. Thermodynamic properties and gas/particle partitioning, Atmos. Environ., 45, 561-577, https://doi.org/10.1016/j.atmosenv.2010.10.013, 2011 b.

Gómez Alvarez, E., Viidanoja, J., Muñoz, A., Wirtz, K., and Hjorth, J.: Experimental Confirmation of the Dicarbonyl Route in the Photo-oxidation of Toluene and Benzene, Environ. Sci. Technol., 41, 8362-8369, https://doi.org/10.1021/es0713274, 2007.

Grigoratos, T. and Martini, G.: Brake wear particle emissions: a review, Environ. Sci. Pollut. Res. Int., 22, 2491-2504, https://doi.org/10.1007/s11356-014-3696-8, 2015.

Healy, R. M., Sciare, J., Poulain, L., Crippa, M., Wiedensohler, A., Prévôt, A. S. H., Baltensperger, U., Sarda-Estève, R., McGuire, M. L., Jeong, C.-H., McGillicuddy, E., O’Connor, I. P., Sodeau, J. R., Evans, G. J., and Wenger, J. C.: Quantitative determination of carbonaceous particle mixing state in Paris using single-particle mass spectrometer and aerosol mass spectrometer measurements, Atmos. Chem. Phys., 13, 9479-9496, https://doi.org/10.5194/acp-13-9479-2013, 2013.

Healy, R. M., Evans, G. J., Murphy, M., Sierau, B., Arndt, J., McGillicuddy, E., O'Connor, I. P., Sodeau, J. R., and Wenger, J. C.: Single-particle speciation of alkylamines in ambient aerosol at five European sites, Anal. Bioanal. Chem., 407, 5899-5909, https://doi.org/10.1007/s00216-014-8092-1, 2015.

Huang, Q., Cai, X., Song, Y., and Zhu, T.: Air stagnation in China (1985-2014): climatological mean features and trends, At- 
mos. Chem. Phys., 17, 7793-7805, https://doi.org/10.5194/acp17-7793-2017, 2017.

Huang, Y., Chen, H., Wang, L., Yang, X., and Chen, J.: Single particle analysis of amines in ambient aerosol in Shanghai, Environ. Chem., 9, 202-210, https://doi.org/10.1071/en11145, 2012.

Kirkby, J., Curtius, J., Almeida, J., Dunne, E., Duplissy, J., Ehrhart, S., Franchin, A., Gagne, S., Ickes, L., Kurten, A., Kupc, A., Metzger, A., Riccobono, F., Rondo, L., Schobesberger, S., Tsagkogeorgas, G., Wimmer, D., Amorim, A., Bianchi, F., Breitenlechner, M., David, A., Dommen, J., Downard, A., Ehn, M., Flagan, R. C., Haider, S., Hansel, A., Hauser, D., Jud, W., Junninen, H., Kreissl, F., Kvashin, A., Laaksonen, A., Lehtipalo, K., Lima, J., Lovejoy, E. R., Makhmutov, V., Mathot, S., Mikkila, J., Minginette, P., Mogo, S., Nieminen, T., Onnela, A., Pereira, P., Petaja, T., Schnitzhofer, R., Seinfeld, J. H., Sipila, M., Stozhkov, Y., Stratmann, F., Tome, A., Vanhanen, J., Viisanen, Y., Vrtala, A., Wagner, P. E., Walther, H., Weingartner, E., Wex, H., Winkler, P. M., Carslaw, K. S., Worsnop, D. R., Baltensperger, U., and Kulmala, M.: Role of sulphuric acid, ammonia and galactic cosmic rays in atmospheric aerosol nucleation, Nature, 476, 429-433, https://doi.org/10.1038/nature10343, 2011.

Li, L., Huang, Z., Dong, J., Li, M., Gao, W., Nian, H., Fu, Z., Zhang, G., Bi, X., Cheng, P., and Zhou, Z.: Real time bipolar time-of-flight mass spectrometer for analyzing single aerosol particles, Int. J. Mass Spectrom., 303, 118-124, https://doi.org/10.1016/j.ijms.2011.01.017, 2011.

Li, Y. J., Sun, Y., Zhang, Q., Li, X., Li, M., Zhou, Z., and Chan, C. K.: Real-time chemical characterization of atmospheric particulate matter in China: A review, Atmos. Environ., 158, 270-304, https://doi.org/10.1016/j.atmosenv.2017.02.027, 2017.

Moffet, R. C., de Foy, B., Molina, L. T., Molina, M. J., and Prather, K. A.: Measurement of ambient aerosols in northern Mexico City by single particle mass spectrometry, Atmos. Chem. Phys., 8, 4499-4516, https://doi.org/10.5194/acp-8-4499-2008, 2008.

Monks, P. S.: Gas-phase radical chemistry in the troposphere, Chem. Soc. Rev., 34, 376-395, https://doi.org/10.1039/b307982c, 2005.

Onasch, T. B., Trimborn, A., Fortner, E. C., Jayne, J. T., Kok, G. L., Williams, L. R., Davidovits, P., and Worsnop, D. R.: Soot Particle Aerosol Mass Spectrometer: Development, Validation, and Initial Application, Aerosol Sci. Technol., 46, 804-817, https://doi.org/10.1080/02786826.2012.663948, 2012.

Pankow, J. F.: Phase considerations in the gas/particle partitioning of organic amines in the atmosphere, Atmos. Environ., 122, 448453, https://doi.org/10.1016/j.atmosenv.2015.09.056, 2015.

Pratt, K. A., Murphy, S. M., Subramanian, R., DeMott, P. J., Kok, G. L., Campos, T., Rogers, D. C., Prenni, A. J., Heymsfield, A. J., Seinfeld, J. H., and Prather, K. A.: Flight-based chemical characterization of biomass burning aerosols within two prescribed burn smoke plumes, Atmos. Chem. Phys., 11, 1254912565, https://doi.org/10.5194/acp-11-12549-2011, 2011.

Qin, X., Pratt, K. A., Shields, L. G., Toner, S. M., and Prather, K. A.: Seasonal comparisons of single-particle chemical mixing state in Riverside, CA, Atmos. Environ., 59, 587-596, https://doi.org/10.1016/j.atmosenv.2012.05.032, 2012.

Rehbein, P. J., Jeong, C. H., McGuire, M. L., Yao, X., Corbin, J. C., and Evans, G. J.: Cloud and fog processing enhanced gas-toparticle partitioning of trimethylamine, Environ. Sci. Technol., 45, 4346-4352, https://doi.org/10.1021/es1042113, 2011.
Silva, P. J., Liu, D.-Y., Noble, C. A., and Prather, K. A.: Size and Chemical Characterization of Individual Particles Resulting from Biomass Burning of Local Southern California Species, Environ. Sci. Technol., 33, 3068-3076, https://doi.org/10.1021/es980544p, 1999.

Smith, J. N., Barsanti, K. C., Friedli, H. R., Ehn, M., Kulmala, M., Collins, D. R., Scheckman, J. H., Williams, B. J., and McMurry, P. H.: Observations of aminium salts in atmospheric nanoparticles and possible climatic implications, P. Natl. Acad. Sci. USA, 107, 6634-6639, https://doi.org/10.1073/pnas.0912127107, 2010.

Song, X. H., Hopke, P. K., Fergenson, D. P., and Prather, K. A.: Classification of single particles analyzed by ATOFMS using an artificial neural network, ART-2A, Anal. Chem., 71, 860-865, https://doi.org/10.1021/ac9809682, 1999.

Tan, P. V., Evans, G. J., Tsai, J., Owega, S., Fila, M. S., Malpica, O., and Brook, J. R.: On-line analysis of urban particulate matter focusing on elevated wintertime aerosol concentrations, Environ. Sci. Technol., 36, 3512-3518, https://doi.org/10.1021/es011448i, 2002.

Tao, J., Zhang, L., Cao, J., and Zhang, R.: A review of current knowledge concerning $\mathrm{PM}_{2.5}$ chemical composition, aerosol optical properties and their relationships across China, Atmos. Chem. Phys., 17, 9485-9518, https://doi.org/10.5194/acp-179485-2017, 2017.

Thorpe, A. and Harrison, R. M.: Sources and properties of non-exhaust particulate matter from road traffic: a review, Sci. Total Environ., 400, 270-282, https://doi.org/10.1016/j.scitotenv.2008.06.007, 2008.

Wang, J., Ge, X., Chen, Y., Shen, Y., Zhang, Q., Sun, Y., Xu, J., Ge, S., Yu, H., and Chen, M.: Highly time-resolved urban aerosol characteristics during springtime in Yangtze River Delta, China: insights from soot particle aerosol mass spectrometry, Atmos. Chem. Phys., 16, 9109-9127, https://doi.org/10.5194/acp16-9109-2016, 2016.

Wang, L., Khalizov, A. F., Zheng, J., Xu, W., Ma, Y., Lal, V., and Zhang, R.: Atmospheric nanoparticles formed from heterogeneous reactions of organics, Supplement, Nat. Geosci., 3, 238242, https://doi.org/10.1038/ngeo778, 2010.

Yao, L., Garmash, O., Bianchi, F., Zheng, J., Yan, C., Kontkanen, J., Junninen, H., Mazon, S. B., Ehn, M., Paasonen, P., Sipila, M., Wang, M., Wang, X., Xiao, S., Chen, H., Lu, Y., Zhang, B., Wang, D., Fu, Q., Geng, F., Li, L., Wang, H., Qiao, L., Yang, X., Chen, J., Kerminen, V. M., Petaja, T., Worsnop, D. R., Kulmala, M., and Wang, L.: Atmospheric new particle formation from sulfuric acid and amines in a Chinese megacity, Science, 361, 278281, https://doi.org/10.1126/science.aao4839, 2018.

Yao, X., Rehbein, P. J. G., Lee, C. J., Evans, G. J., Corbin, J., and Jeong, C.-H.: A study on the extent of neutralization of sulphate aerosol through laboratory and field experiments using an ATOFMS and a GPIC, Atmos. Environ., 45, 6251-6256, https://doi.org/10.1016/j.atmosenv.2011.06.061, 2011.

You, Y., Kanawade, V. P., de Gouw, J. A., Guenther, A. B., Madronich, S., Sierra-Hernández, M. R., Lawler, M., Smith, J. N., Takahama, S., Ruggeri, G., Koss, A., Olson, K., Baumann, K., Weber, R. J., Nenes, A., Guo, H., Edgerton, E. S., Porcelli, L., Brune, W. H., Goldstein, A. H., and Lee, S.-H.: Atmospheric amines and ammonia measured with a chemical ionization mass 
spectrometer (CIMS), Atmos. Chem. Phys., 14, 12181-12194, https://doi.org/10.5194/acp-14-12181-2014, 2014.

Zhang, G., Bi, X., Chan, L. Y., Li, L., Wang, X., Feng, J., Sheng, G., Fu, J., Li, M., and Zhou, Z.: Enhanced trimethylamine-containing particles during fog events detected by single particle aerosol mass spectrometry in urban Guangzhou, China, Atmos. Environ., 55, 121-126, https://doi.org/10.1016/j.atmosenv.2012.03.038, 2012. 